\title{
CHALLENGES IN FORENSIC DETECTION OF FORGERY BY DISAPPEARING INK
}

\section{Forensic Science}

Sujay Saha*

\section{Ashok Kumar}

Barik

\section{Kananbala Jena}

Dy. Director \& Scientist 'D', Central Forensic Science Laboratory, Kolkata-700014. *Corresponding Author

Asst. Director \& Scientist 'C', Central Forensic Science Laboratory, Kolkata-700014.

Dy. Director \& Scientist 'D', Central Forensic Science Laboratory, Kolkata-700014.

\section{ABSTRACT}

Common People have used ink and paper for making notes for a long time. Due to public trust on permanency and authenticity of records written in ink, handwritten entries on different types of printed banking instruments has enjoyed confidence of both banks and customers for a long time. But, ink writings could be manipulated to achieve intentions of fraudsters without knowledge of the writer.

Fraudsters first erase the ink writing by different methods and cover the area with new writings. Common methods to erase writings are physical and chemical erasures. In the cases where physical erasures are done, either traces of ink left on the paper or the signs of abrasion on the paper attracts the attention of examiner. Chemical erasures mostly lead to change in tint of the surface in the affected area. Both chemical and physical erasure leads to loss of micro printing done as a security feature in the area. Recently, we came across a case where earlier writings were changed without any easily detectable changes in normal light. Market survey reveals that disappearing ink pens are commercially available which can disappear after writing on paper in matter of hours. Since no physical abrasion is required or chemicals were used to erase the same, no tell tale signs of either kind of erasure is readily detected. This paper discusses how one such case could be detected and suggests directions to design a module so that these types of cases do not go undetected.

\section{KEYWORDS}

physical erasure, chemical erasure, disappearing ink

\section{INTRODUCTION:}

It is common to find changed writings in the course of forensic document examination and this act of making changes in documents with the intention of cheating is considered as forgery. Existing writings can be changed by physical or chemical process or even by digitally assisted manipulation. Some methods involve lifting existing ink lines with sharp objects like pins, knifes or by blunt objects like rubber. In this process paper surface gets changed and disturbed paper fibers can be easily detected by visual examination when observed under reasonable enlargement. Microscopic enlargements may also reveal remnants of earlier ink strokes. Household chemicals such as brake oil, acetone, baking soda solution and alcohol can be used to remove ink. Market survey reveals specialised products are available as 'ink and stain removers' having different brand names to achieve this task. The solved cases generally show a change in tint where the chemical is applied. Chemical erasure can be further investigated by various lighting conditions and reveal more details. Earlier studies also reveal use of chemicals like sodium hydroxide for decipherment of earlier writings. This methodology might not be useful, particularly when there is a chance to destroy the evidential value of documents by affecting the disputed writing portion.

In the case under consideration a forgery by using a disappearing ink was studied. There were no indications of manipulation to the naked eye as well as when observed under normal light with reasonable magnification. The present paper discusses how the manipulation could be detected by non-destructive method and why it's alarming.

\section{Details of the case Examination}

In the case registered for document examination in three bank cheques (marked Q1 to Q3) it was alleged that the cheques were issued only for a few hundred rupees as post-dated account payee cheques. But, lakhs were withdrawn from the account using these cheques by alteration of earlier writings including name, amount and figures of date in the said three cheques. It was established that the earlier writings were written using disappearing ink

\section{Method of case Examination:}

For Examination of the case stereomicroscopic examination technique, optical method and spectral comparison methods were applied using following instruments.

a) Video Spectral Comparator (VSC-5000)

b) Stereomicroscope (Leica Q Win Series)
3.1 Exposure to flood light with $2 \mathrm{X}$ magnification of body writings of cheque marked Q3

RESULT: No indication of previous writings found.

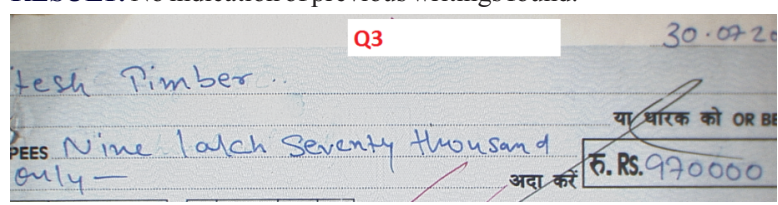

Figure 1: A view of cheque marked Q3 in flood light

3.2 Exposure to UV spot light of writings in Pay and Rupees line of cheque marked Q3

RESULT: Fluorescence visible below existing writings indicating presence of earlier writings.

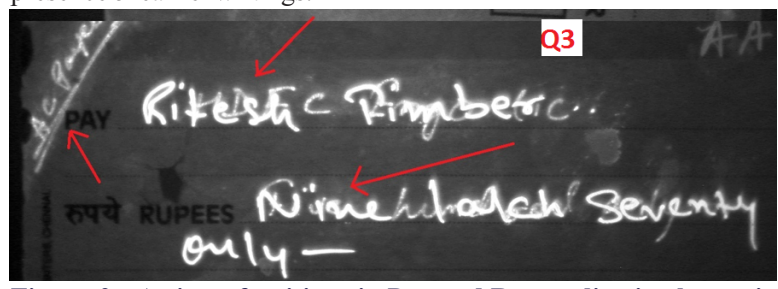

Figure:2 A view of writings in Pay and Rupees line in cheque in UV light

3.3 Exposure to UV spot light of writings in Figures of Date and Amount line of cheque marked Q3

RESULT: Fluorescence visible below existing writings indicating presence of earlier writings.

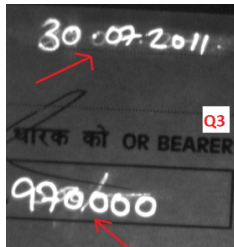

Figure:3 A view of writings in Date and figures of Amount line in UV light 
3.4 Microscopic examination under flood light of cheque marked Q3

RESULT: Safety printing is not disturbed and remnants of earlier writings visible

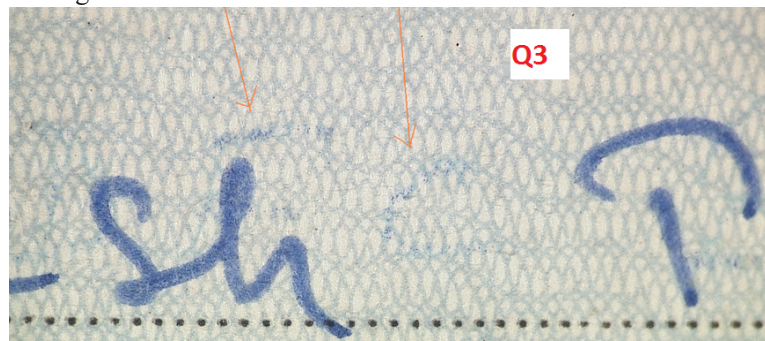

Figure:4 A microscopic view of safety printing

3.5 Microscopic examination under co-axial light source of cheque marked Q2

RESULT: Disturbances in paper fiber observed in some portion

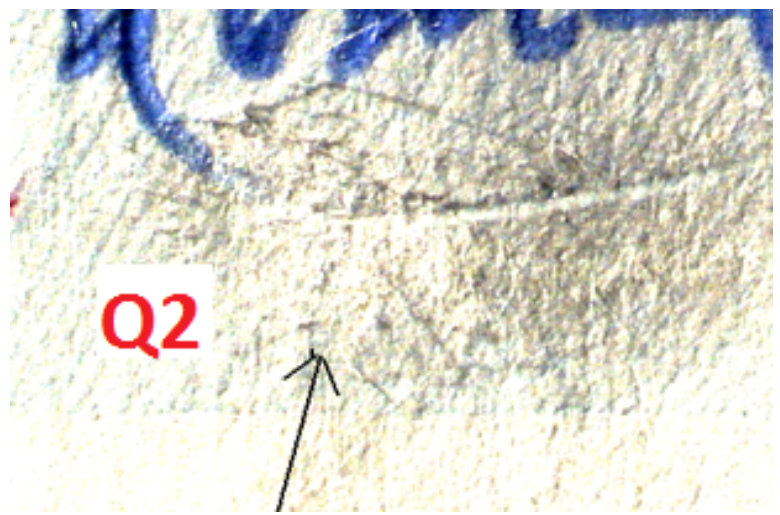

Figure 5: A view of a portion of cheque marked $Q 2$ under co-axial light source

3.6 Microscopic examination under co-axial light source of cheque marked Q1

RESULT: Indentations observed in portion of figures of amount

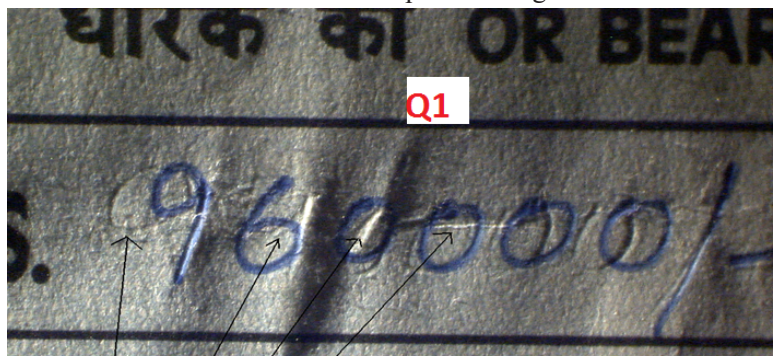

Figure 6: A view of a portion of cheque marked Q1 under co-axial light source

\section{Observation:}

a. Some indentation was found in one of the cheques under co-axial light sources which confirms existence of earlier writings also.

b. Fiber disturbances at places in some of the cheques observed indicates use of Physical erasures also.

c. No disturbance to micro printing in the background of cheques rules out use of aqueous based chemical erasure.

d. Remnants of earlier ink present in some of the cheques indicate earlier writings.

e. Presence of earlier writings also confirmed by UV fluorescence.

\section{Conclusion:}

1. Remnants of ink found on the instrument suggest that all the traces of earlier writing are not erased. Therefore, detailed visual examination may be included as a preliminary method even after several months, though; disappearing inks claim not to leave any trace after few hours.

2. Fluorescence seen in UV light is prominent and easily readable suggesting permanent changes happen when these inks react with surface of paper, though invisible to naked eye. So, a cursory examination of suspected documents as a whole by UV light can confirm presence of this type of ink.

3. The trends of cases show such ink pens are now-a-days used for banking instrument forgery and need an in depth study. Thermo chromic ink/disappearing ink studies should be done vis-à-vis use of aqueous based erasure or physical erasure.

4. Undisturbed security printing alone cannot be basis of clearance to any banking instrument.

\section{Further scope for work:}

One of the methods for detecting forgery in banking instruments is disturbances in safety printing. Therefore, it is necessary to introduce security features which can readily react to disappearing ink and leave a visible permanent mark. There is also scope to study non destructive modes to make these inks reappear. These methods will increase public and banker's confidence and work as a deterrent to such crimes.

\section{REFERENCES:}

Huber RA and Headrick AM. (1999). Handwriting Identification: Facts and Fundamentals, CRC Press.

2. Manal Abd-EAziz Abd-ElZaher, Different types of inks having certain medicolegal importance: Deciphering the faded and physically erased handwriting, Egyptian Journal of Forensic Sciences, 2014; 4(2):39-44

3. Deshpande Hemantini, Mulani Khudbudin, Brazilian Journal of Forensic Sciences, Medical Law and Bioethics 2018; 7(3):156-161.

4. Pandey RK, Sankhla MS, Kumar R. Forensic investigation of suspected document fo alteration, erasures \& obliteration. Galore International Journal of Applied Sciences \& Humanities. 2018;2(1): 46- 50

5. Sushma Upadhyay, Farheen Fatima, Simple Techniques to Reveal Invisible Ink in Forensic Science Research J. Pharm. and Tech 2017; 10(12):4209-4210. 